\title{
Apprehensive and frustrative uses of before $e^{*}$
}

\author{
Chloé Tahar \\ Institut Jean Nicod, ENS, EHESS, PSL \\ University, CNRS
}

\begin{abstract}
Prior research has shown that the interpretational possibilities of the temporal connective before range from factual to non-factual. In this paper, I look at how context-dependent inferences can enrich the meaning of non-factual before ('avant que') clauses in French. My proposal is that, in a sentence like [ $q$ [before $p]$ ], non-factual before may receive two pragmatically enriched uses (i) an apprehensive use, where the agent responsible for $q$ has the goal of avoiding $p$ (after Anderbois \& Dabkowski 2020); (ii) a frustrative use, where it is contrary to the expectations of the agent responsible for $q$ that $p$. Going further, I address the question of expletive negation in avant que clauses, arguing that its role is to put emphasis on the connective's invited inferences of negative (teleological or stereotypical) preference. Finally, I generalize the account to other contexts where expletive negation occurs in French.
\end{abstract}

Keywords: before clauses, expletive negation, modality, context-dependency

\section{Introduction}

Previous works on before clauses (Heinämäki 1974; Ogihara; Beaver \& Condoravdi 2003; Condoravdi 2010) have underlined how contextual factors play a significant role in determining whether before clauses are to be interpreted as factual or as non-factual. Building on this distinction, this paper presents evidence from attested examples that, depending on how the extra-linguistic context affects its interpretation (see also Rubinstein 2012; Yanovitch 2013), non-factual before can receive more than one pragmatically constrained use.

* This work has benefitted from extensive discussion with my advisor Alda Mari and from the much appreciated help of Salvador Mascarenhas and Claire Beyssade. This paper also owes to the insights of Maribel Romero. Many thanks also to Regine Eckardt, Doris Penka and Kajsa Djarv for their useful comments and suggestions, as well as to the SALT anonymous reviewers and audience. I also thank the FrontCog ANR-17-EURE-0017. 
Apprehensive and frustrative uses of before

The connective before can receive three main types of uses: (i) a consecutive use, associated with a factual interpretation, (ii) an apprehensive use and (iii) a frustrative use, both associated with a non-factual interpretation. The following examples illustrate each of them.

a. Jules was watching TV before he went to bed.

b. Jim must catch the Greek vase before it falls.

c. Catherine won't go to bed before she has found her pearl bracelet.

When the connective receives a basic consecutive use, see (1-a), it expresses that two states of affairs follow each other in time (first, Jules watches TV, then he goes to bed). When the connective receives an apprehensive use, see (1-b), it expresses a relation of negative purpose between the main clause and the subordinate clause. The main clause aims at avoiding the state of affairs described in the subordinate clause (to put it roughly, Jim must catch the Greek vase so that it does not fall). When the connective receives a frustrative reading, see (1-c), it expresses a relation of negative reason between the two clauses. The main clause results from the expectation that the state of affairs described in the subordinate clause will not happen (again, using an approximation, Catherine will not go to bed for the reason that she does not find her pearl bracelet).

On what grounds does the connective before permit such a range of uses? In this paper, I argue that the two pragmatically enriched uses of non-factual before, namely the apprehensive and the frustrative, follow from the temporal semantics of the connective. Casting the temporal semantics of before within Krifka (2010)'s model for German bevor, the before clause has a prospective meaning, which makes it inherently nonveridical, regardless of its variability in factuality (Giannakidou (1998) et seq.). As a matter of fact, I assume, building on Beaver \& Condoravdi (2003), that the subordinate proposition $p$ is evaluated with respect to a historical modal domain, where there is a possibility that $p$ as well as a possibility that not- $p$. My point is that the extra-linguistic context may further supply the modal domain under consideration with a goal-oriented or a prediction-oriented ordering, which ranks the negative possibility as the best. The context supplies the apprehensive use of before with a negative teleological ordering and the frustrative use with a negative stereotypical ordering.

Besides, I will show how expletive negation is a cornerstone of the differences in the various uses of the connective before. In French, avant que clauses are a context in which expletive negation - a solitary negation marker with a restricted distribution, that does not reverse the truth-value of the clause it occurs in - can occur. In naturally occurring data, expletive negation is more frequent in avant que clauses that receive an apprehensive or frustrative use. Along with several others, 
my take on the question of expletive negation is to consider it as a 'revealing agent', the value of which is to track a specific semantic component in the predicates with which it occurs (cf. the 'licenser question', Ladusaw 1996; Israel 1996; Giannakidou 1998). I will argue that expletive negation is semantically sensitive to (nonveridical) contexts that express negative preferences, within and beyond avant que clauses.

This paper is structured as follows. Section 2 provides an informal description of the three main uses of avant que in French. Section 3 proposes a formal analysis for each of these uses. Section 4 addresses the sensitivity question of expletive negation.

\section{The range of uses of avant que}

This section provides a description of three main uses of the connective avant que in context. It is not my intention to cover every use that the connective may have, but to identify and describe the most relevant ones in the ordinary use of this connective.

\subsection{The consecutive use}

The consecutive use has a meaning which is strictly temporal. Example (1-a), which translates to (2) in French, illustrates this use.

(2) Jules regardait la télé avant qu' il parte se coucher. Jules watch-IPFV the TV before that he go-SBJV REFL go-to-bed-INF 'Jules was watching TV before he went to bed.'

The consecutive use of avant que is factual. In other terms, the avant que clause is interpreted under a retrospective viewpoint (Giannakidou \& Zwarts 1999; Giannakidou 2014), as it refers to a (past or present) fact. It is convenient to give examples of the consecutive use of avant que where the main clause is in the past tense, as it shifts the temporal interpretation of the dependent avant que clause to a retrospective viewpoint. Example (2) is factual, as the avant que clause implies that Jules went to bed in the actual world. Example (3) as well, as the avant que clause implies that the speaker actually started to work.

(3) Ce matin (...) je mangeais de fort bon appétit un plat de this morning (...) I eat-1SG.IPFV of strongly good appetite a dish of pâtes (...) avant que je me mette au travail. pasta (...) before that I REFL put-1 SG-SBJV to work 'This morning I've been eating a pasta dish with a strong appetite before I started to work.' 1

1 (Quignard, Pascal, Le salon de Wurtenberg, 1986) 
Apprehensive and frustrative uses of before

As a consequence, the consecutive use conveys that the avant que clause event follows the main clause event in time, that it takes place subsequently. In example (2), the main clause and the avant que clause denote events that follow each other in time: first, Jules watches TV and then, he goes to bed. In (3), the speaker eats a pasta dish at first and starts to work subsequently. Summing up, the consecutive use of avant que denotes a relation of consecution between the main clause and the dependent clause, conveying that, first $q$ and not- $p$, and then $p$.

\subsection{The apprehensive use}

Turning to the apprehensive use of avant que, already illustrated with example (1-b), which translates to (4) in French, it must be noted that the use of expletive negation is statistically frequent with this use (although it remains optional). The brackets, in the example below, are here to indicate the optionality of expletive negation.

Jim doit attraper le vase grec avant qu' il (ne) tombe.

Jim must catch the vase greek before that it EXNEG fall-3SG.SBJV

'Jim must catch the Greek vase before it falls.'

Two main characteristics of the apprehensive use of avant que can be singled out.

First, the apprehensive use of avant que is non-factual, as the dependent clause is interpreted under a prospective viewpoint (again, see Giannakidou \& Zwarts 1999 and Giannakidou 2014), since it describes an event that is expected to happen but that did not yet happen at the time of the main clause (which generally coincides with the utterance time). With this use, the speaker does not know whether the avant que clause event will take place. Example (4) illustrates such a non-factual reading: it conveys that - since the vase didn't fall by the time of the main clause (that is to say, when Jim has to catch the vase) - the vase may or may not fall in the future course of events (depending on the outcome of Jim's catching the vase). In fact, both $p$ and not- $p$ remain live possibilities.

Second, the apprehensive use of avant que conveys a negative purposive inference. Apprehensive (or negative purposive) meaning is, for the most, conveyed by biclausal constructions (as discussed by Lichtenberk 1995; Angelo \& SchultzeBerndt 2016; Vuillermet 2018; Kuteva, Aarts, Popova \& Abbi 2019; Anderbois \& Dabkowski 2020). Negative purposive inferences typically arise in structures that 'connect a clause encoding an apprehension-causing situation to a preceding clause encoding a [preemptive] situation' (Lichtenberk 1995: 295). As a matter of fact, with the apprehensive use of avant que, the main clause describes a preemptive situation. In general, the 'precautionary' clause is constructed with an imperative verb or a priority modal (after Portner's (2007) label for deontic, teleological and bouletic modals). The precautionary clause thus urges the addressee (or a third 
person) to undertake a certain practical action. In example (4), the main clause is modalized with the priority modal devoir (translating to must), which assigns the agent the duty to catch a vase (on the verge of falling). For other examples, look at the main modalized clause in (5), also constructed with devoir, which assigns the agent the duty to go back to her highschool. Look also at the main clause of (6), modalized with the locution faire mieux de (which translates to prioritative should better, or ought to), where the speaker suggests the addressee to give her back the car keys, instead of keeping them (at the risk of unwanted consequences).

Justine devait regagner [son lycée] avant que ses parents Justine must-PST get-back-to her highschool before that her parents ne préviennent la police.

EXNEG warn-3PL.SBJV the police

'Justine had to get back to her high school before her parents called the police.' $^{2}$

(6) Vous feriez mieux de me donner les clés [de la voiture] tout de you should better to CL.1SG give the keys of the car all of suite, avant que je ne fasse des histoires. next before that I EXNEG do-1SG.SBJV DEM stories.

'You should better give me the car keys right now before I make a fuss.' 3

Going back to the dependent avant que clause, it generally describes a situation that the agent of the main clause has the purpose of avoiding (by undertaking the preceding preemptive action). In example (4), the agent catches the vase with the purpose of avoiding that it falls on the floor and gets smashed into pieces. In (5), the agent is under the obligation to go back to her highschool, with the purpose of avoiding that her parents worry and call the police. As for (6), the agent is advised to give the speaker her keys back with the purpose of avoiding making her angry.

Summing up, with the apprehensive use of avant que, the avant que clause event is not actualized at the time of the main event and it may remain non-actualized subsequently. Indeed, the main clause describes a precautionary situation that is undertaken by the agent in control with the purpose of avoiding the subsequent (undesirable) event described by the avant que clause.

\subsection{The frustrative use}

The frustrative use of avant que was illustrated with example (1-c), which translates to French (7). With the frustrative use as well, expletive negation is statistically

2 (Manoeuvre, Phillipe, L'enfant du rock, 1985)

3 (Koltès, Jean-Marie, Quai Ouest, 1985) 
Apprehensive and frustrative uses of before

frequent although optional.

$$
\begin{aligned}
& \text { Catherine ne se couchera pas avant qu' elle (n') } \\
& \text { Catherine NEG REFL go-to-bed-3SG.FUT not before that she EXNEG } \\
& \text { ait retrouvé son bracelet de perles. } \\
& \text { have-3SG.SBJV found her bracelet of pearls } \\
& \text { 'Catherine won't go to bed before she has found her pearl bracelet.' }
\end{aligned}
$$

Again, two main characteristics:

First, the frustrative use of avant que clauses is non-factual. To explain it like previously, the avant que clause is interpreted under a prospective viewpoint: the event it introduces is not actualized at the time of the main clause and it may or may not be actualized at reasonably probable alternatives. For instance, example (7) implies that Catherine didn't find her pearl bracelet at the time of the main clause and that she may or may not find it later. Both $p$ and not- $p$ remain live possibilities.

Second, the frustrative use conveys a negative reason inference. Frustrative meaning arises as the avant que clause expresses the negative reason behind the action described by the main clause. Indeed, this use of avant que connects a frustration-causing situation to a preceding clause denoting a coercitive situation. A coercitive situation can be defined as a measure taken by the agent in control that constrains or inhibits her own behavior (or that of others). This coercitive measure generally consists in a negative event, describing an 'active inaction', that is to say a situation in which the agent has the 'strong volition not to do the denoted action' (see Zaradzki 2020). For instance, in (7), Catherine is actively not going to bed, in the sense that it could be expected from her to go to bed, but she is depriving herself from doing so. In (8) as well, the agent of the main clause (the speaker) is refraining from leaving, she is making an effort not to leave. As a matter of fact, the remainder of the text specifies that she is refusing to make way for another person to go where he's heading to.

(8) Si, j' exige des excuses. Je ne déboucherai[=partirai] pas avant Yes, I request DEM apologies. I NEG leave-1SG.FUT not before qu' il ne vous ait demandé pardon. that he EXNEG CL.2PL AUX-3SG asked forgivance 'Yes, I demand an apology. I will not leave before he apologized to you.'

Going back to the avant que clause, it involves a (desirable) situation that the agent of the main clause expects not to happen (an 'unrealized goal', see Kroeger 2017; Overall 2017). The expected non-actualization of the avant que clause represents the personal motivation (see also Verstraete 2008) for the agent's decision to undertake

4 (Aymé, Marcel, Nouvelles complètes, 2002) 
the coercitive action described by the main clause. In other words, the frustrative avant que clause provides an explanation (a negative expectation) for the preceding coercitive clause. In (7), for instance, Catherine, the agent of the main clause, considers it most likely that she will not find her pearl bracelet, and for this reason she is actively refraining from going to bed (since she needs to stay awake to keep searching for it). In (8), the coercitive action undertaken by the agent of the main clause (that of standing in someone else's way) is motivated by the agent's expectation that this person will not apologize for his (offensive) behavior. ${ }^{5}$ In (9), the agent is actively refraining from entering her father's office for the reason that she expects that her father will not forgive her shouting at him.

Mon cher papa, je me meurs de chagrin de la sotise que j' my dear dad, I REFL die-1SG of grief from the folly that I

ai faite de crier. Je n' ose rentrer avant que vous

AUX.1SG done of shout. I NEG dare-1SG enter before that you

ne aiez pardonné.

EXNEG CL.1SG AUX.1SG.SBJV forgiven.

'My dear dad, I'm dying of grief for having behaved badly by yelling at you. I dare not enter before you forgave me.' 6

Summing up, with the frustrative use of avant que, the avant que clause event is not actualized at the time of the main event and it may remain non-actualized subsequently. Indeed, the main clause describes a coercitive situation, caused by the agent's expectation that the intended situation described by the avant que clause will not happen.

\section{Deriving the multiple uses}

This section makes the case for a multi-layered account of the semantics of before in an attempt to address the question of how the core prospective temporal meaning of the connective is related to its consecutive use on a par, and to its apprehensive and frustrative uses, on the other, via different types of inferences. Section 3.1 introduces the several semantic ingredients that are necessary to build the multiple uses that the connective before has in context. Section 3.2 derives the consecutive use. Section 3.3 and 3.4 derive the apprehensive and frustrative use.

5 Note that, in (8), the coercitive action undertaken by the agent (indirectly) aims at coercing a third person into bringing about the content of the avant que clause (namely, into apologizing). At the level of the speech-act, the biclausal construction can be analyzed as a threat.

6 (Diderot, Denis, Lettres à Sophie Volland, 1774) 
Apprehensive and frustrative uses of before

\subsection{Semantic ingredients}

A (prospective) temporal meaning I stand by the line of reasoning of Anscombe (1964); Ogihara; Del Prete (2008) and Krifka (2010), who have previously argued that before names a relation between an event that is not (yet) actualized at or before the time at which the main clause is instantiated, and the main clause event. Within this perspective, the time variable at which the before clause is to be interpreted gets its value from not being anterior or simultaneous to the time at which the main clause is true, see the entry (10) from Krifka 2010: the before clause denotes a future event with respect to the main clause event.

$$
\begin{aligned}
& {[[\mathrm{A} \text { before } \mathrm{B}]]=} \\
& \lambda \mathrm{t}\left[[[\mathrm{A}]](\mathrm{t}) \wedge \neg \exists \mathrm{t}^{\prime}\left[\mathrm{t}^{\prime} \leq \mathrm{t} \wedge[[\mathrm{B}]]\left(\mathrm{t}^{\prime}\right)\right]\right.
\end{aligned}
$$

The entry (11) rephrases the former entry to make before operate on propositions rather than events. ${ }^{7}$ The entry (11) conveys that the before clause is not instantiated for all times that precede or are simultaneous to the time $t$ of the world-time pair $\langle w, t\rangle$ at which the main clause is instantiated (which is, in general, the world-time pair of the utterance context).

$$
\begin{aligned}
& {[\text { before } \rrbracket=\lambda p \cdot \lambda q \cdot \lambda w \cdot \lambda t} \\
& \langle w, t\rangle \in q \text { and } \neg \exists t^{\prime}\left[t^{\prime} \leq t \text { such that }\left\langle w, t^{\prime}\right\rangle \in p\right]
\end{aligned}
$$

Summing up, the temporal meaning of the connective, which is 'conceptually negative from the point of view of the event in the main clause' (Thompson, Longacre \& Hwang 2007: 247), denotes a prospective temporal relation.

A (nonveridical) definedness condition The temporal meaning of before being intrinsically prospective, the nonveridicality of before is absolute (Giannakidou 1998: 109), irrespective of its different interpretational possibilites (i.e., its optional factuality). In effect, prospective meaning is (subjectively) nonveridical (see Giannakidou 2014, Giannakidou \& Mari 2013; Giannakidou \& Mari 2017b). Nonveridicality is defined as the property of an operator that do not entail the truth of the proposition it takes as argument, in the sense of Zwarts (1995); Giannakidou (1998), Giannakidou (1999), with respect to an epistemic model, in the sense of Giannakidou (2011); Giannakidou \& Mari (2016); Giannakidou \& Mari (2017a). Further, the intrinsic nonveridicality of the before-clause is what accounts for its subjunctive mood and NPI licensing behavior (see Giannakidou 1998; Giannaki-

7 Making use of Beaver \& Condoravdi (2003)'s notation $\langle w, t\rangle \in p$, to express that a proposition $p$ is true in a world-time pair $\langle w, t\rangle$. 
dou 2009, et seq.). ${ }^{8}$ Building on Beaver \& Condoravdi (2003), I assume that the nonveridicality of the before clause is relativized to an historical modal base, which concerns alternative course of future events which are reasonably probable given the course of events up to the world-time pair $\langle w, t\rangle$ at which the main event is instantiated. This historical modal base, noted alt $(w, t)$, is partitioned between $p$ and not- $p$-worlds (see also Condoravdi 2001). As Beaver \& Condoravdi (2003) note, historical alternatives can also be conceived as epistemic alternatives about what the course of events may be, from the perspective of the epistemic model of the speaker at the world-time pair of the main clause (but see Giannakidou \& Mari (2017b) for a different perspective). In my proposal, the nonveridical layer of meaning is captured as a definedness condition intrinsic to the meaning of the connective (contra Beaver \& Condoravdi (2003)), see (12).

Definedness conditions for before: $\exists w^{\prime} \in \operatorname{alt}(w, t): p\left(w^{\prime}\right)$ and $\exists w^{\prime \prime} \in \operatorname{alt}(w, t): \neg p\left(w^{\prime \prime}\right)$

Krifka (2010) proposes that the factual reading of before comes as an implicature, conveying that there is a time $t^{\prime \prime}$ that follows the time $t$ at which the main clause is instantiated, such that the before clause event is true at $t^{\prime \prime}$. I will build on his proposal.

An invited (dispreferential) inference Recently, Angelo \& Schultze-Berndt (2016) have investigated how a temporal marker of consecution can conventionalize, via certain inferential mechanisms, an apprehensive reading. We follow these authors in assuming that the dispreferential inferences involved in some of the uses of before are invited inferences, that first arise in specific contexts to end up conventionalized. My point is that the the connective before conventionalizes inferences that supply the historical modal domain with respect to which $p$ is evaluated with a secondary conversational background or 'ordering source' à la Kratzer (1991); Portner (2009). Not every conversational background may impose an ordering upon a historical modal base and certain conversational backgrounds happen to be more natural (see also Yanovitch 2013). This is the case of goal-oriented (see Mari 2017; Giannakidou \& Mari 2021) and prediction-oriented (see Giannakidou \& Mari 2013) conversational backgrounds. With the apprehensive use, the historical modal domain is assigned a teleological ordering ranking the not- $p$-alternative as the best. With the frustrative use, the historical modal domain is assigned a stereotypical ordering ranking the not- $p$-alternative as the best. Note that my proposal, inspired by that of Anderbois \& Dabkowski (2020), ascribes the dispreferential attitude to the agent in control of the action described in the main clause. Moreover, to capture those not- $p$-worlds in

8 I am grateful to Hans Kamp and Alice ter Meulen for calling my attention to this point. 
Apprehensive and frustrative uses of before

the modal base $(\mathscr{M})$ which are Best-ranked with respect to the ordering source $(\mathscr{O})$, I will be using a notation à la Portner (2009); Mari (2017); Giannakidou \& Mari (2021): $\operatorname{Best}_{\mathscr{O}}(\mathscr{M})$.

\subsection{Deriving the consecutive use}

I will start by the semantics for the consecutive use of avant que, as in (13).

Jules regardait la télé avant qu' il parte se coucher. Jules watch-IPFV the TV before that he go-SBJV REFL go-to-bed-INF 'Jules was watching TV before he went to bed.'

The core temporal meaning of this use, as given in (14-a) comes with the definedness condition that the avant que clause is nonveridical, as given in (14-b), as well as with a factual implicature (14-c).

$[[$ avant que consecutive $]]=\lambda p \cdot \lambda q \cdot \lambda w \cdot \lambda t$.

a. $\quad$ Temporal meaning: $\langle w, t\rangle \in q$ and $\neg \exists t^{\prime}\left[t^{\prime} \leq t\right.$ such that $\left.\left\langle w, t^{\prime}\right\rangle \in p\right]$

b. Definedness condition: $\exists w^{\prime} \in \operatorname{alt}(w, t): p\left(w^{\prime}\right)$ and $\exists w^{\prime \prime} \in \operatorname{alt}(w, t)$ : $\neg p\left(w^{\prime \prime}\right)$

c. Implicature: $\exists t^{\prime \prime}\left[t<t^{\prime \prime}\right.$ such that $\left.\left\langle w, t^{\prime \prime}\right\rangle \in p\right]$

Applying this semantics to (13) (regardless of tense and mood) we obtain:

a. $\quad[\mathrm{PAST}$ (Jules regarde la télé) $]]=\lambda w$. Jules is watching TV in $w$

b. $\quad[$ SBJV (il part se coucher) $)]=\lambda w$. Jules goes to bed in $w$

c. $\quad[$ avant qu'il parte se coucher $]]=\lambda q \cdot \lambda w . \lambda t$.

(i) Temporal meaning: $\langle w, t\rangle \in q$ and $\neg \exists t^{\prime}\left[t^{\prime} \leq t\right.$ such that Jules goes to bed at $t^{\prime}$ in $w$ ]

(ii) Definedness condition: $\exists w^{\prime} \in \operatorname{alt}(w, t)$ : Jules goes to bed in $w^{\prime}$ and $\exists w^{\prime \prime} \in \operatorname{alt}(w, t)$ : Jules does not go to bed in $w^{\prime \prime}$

(iii) Implicature: $\exists t^{\prime \prime}\left[t<t^{\prime \prime}\right.$ such that Jules goes to bed at $t^{\prime \prime}$ in $\left.w\right]$

The main clause in (15-a) conveys that Jules is watching TV (in the past). The (subjunctive) clause in (15-b), that avant que takes as argument, conveys that Jules goes to bed. The consecutive avant que clause in (15-c) takes the main clause as argument and conveys the temporal meaning that, for all times preceding or simultaneous to the time at which the main clause is instantiated, Jules didn't go to bed. (15-c) comes with the definedness condition that, given the course of events up to the time at which the main clause is instantiated, Jules has a reasonable chance of going to bed as well as a reasonable chance of not going to bed. Additionally, the avant que clause in (15-c) comes with the implicature that there is some time, 
subsequent to that of the main clause, at which Jules goes to bed (in the actual world).

$$
[[(13)]]=\lambda w \cdot \lambda t \text {. }
$$

a. Temporal meaning: Jules is watching TV in $w$ at $t$ and $\neg \exists t^{\prime}\left[t^{\prime} \leq t\right.$ such that Jules goes to bed at $t^{\prime}$ in $w$ ]

b. Definedness condition: $\exists w^{\prime} \in \operatorname{alt}(w, t)$ : Jules goes to bed in $w^{\prime}$ and $\exists w^{\prime \prime} \in \operatorname{alt}(w, t):$ Jules does not go to bed in $w^{\prime \prime}$

c. Implicature: $\exists t^{\prime \prime}\left[t<t^{\prime \prime}\right.$ such that Jules goes to bed at $t^{\prime \prime}$ in $\left.w\right]$

Overall, (16) conveys that Jules is watching TV (in the past) and that, for all times preceding or simultaneous to the time at which Jules is watching TV, Jules didn't go to bed. The definedness condition of (16) conveys that, given the course of events up to the time where Jules is watching TV, he has a reasonable chance of going to bed as well as of not going to bed. Finally, (16) conveys the implicature that Jules did go to bed at a time subsequent to that of the main clause. The semantic entry (14) thus does justice to the meaning of temporal consecution between the main clause and the avant que clause that this use conveys.

\subsection{Deriving the apprehensive use}

Let's move on to the apprehensive use of avant que, as in (17).

Jim doit attraper le vase grec avant qu' il (ne) tombe. Jim must catch the vase greek before that it EXNEG fall-3SG.SBJV 'Jim must catch the Greek vase before it falls.'

With the apprehensive use, the temporal meaning, as given in (18-a), comes with the definedness condition that the avant que clause is nonveridical, see (18-b). Additionally, this use is analyzed as involving an invited inference of negative purpose, given in (18-c). This invited inference is modelled after Anderbois \& Dabkowski (2020)'s recent proposal for apprehensive adjunct clauses. What the negative purposive inference in (18-c) conveys is that all the historical alternatives of $w$ at $t$ which are most compatible with the goals of the agent $i$, responsible for the (preemptive) action described by $q$, are not- $p$-worlds.

$\left[\left[\right.\right.$ avant $\left.q u e_{\text {apprehensive }}\right]=\lambda p \cdot \lambda q \cdot \lambda w \cdot \lambda t$.

a. Temporal meaning: $\langle w, t\rangle \in q$ and $\neg \exists t^{\prime}\left[t^{\prime} \leq t\right.$ and $\left.\left\langle w, t^{\prime}\right\rangle \in p\right]$

b. Definedness condition: $\exists w^{\prime} \in \operatorname{alt}(w, t): p\left(w^{\prime}\right)$ and $\exists w^{\prime \prime} \in \operatorname{alt}(w, t)$ : $\neg p\left(w^{\prime \prime}\right)$

c. Invited inference: $\forall w^{\prime} \in \operatorname{Best}_{\mathrm{TELEO}_{i, q}}(\operatorname{alt}(w, t)): \neg p\left(w^{\prime}\right)$ 
Apprehensive and frustrative uses of before

$$
\text { (presupposition: } \exists i \text { : } \operatorname{RESP}(i, q) \text { ) }
$$

Applying this semantics to (17) (regardless of tense and mood, as well as of expletive negation) we obtain:

$$
\begin{array}{ll}
\text { a. } & {[[\text { Jim doit attraper le vase }]]=\lambda w . \text { Jim must catch the vase in } w} \\
\text { b. } & {[[\text { SBJV }(\text { il tombe })]=\lambda w . \text { the vase falls in } w} \\
\text { c. } & [\text { avant qu'il }(\text { ne }) \text { tombe }]]=\lambda q . \lambda w . \lambda t .
\end{array}
$$

(i) Temporal meaning: $\langle w, t\rangle \in q$ and $\neg \exists t^{\prime}\left[t^{\prime} \leq t\right.$ such that the vase falls at $t^{\prime}$ in $w$ ]

(ii) Definedness condition: $\exists w^{\prime} \in \operatorname{alt}(w, t)$ : the vase falls in $w^{\prime}$ and $\exists w^{\prime \prime} \in \operatorname{alt}(w, t):$ the vase does not fall in $w^{\prime \prime}$

(iii) Invited inference: $\forall w^{\prime} \in \operatorname{Best}_{\mathrm{TELEO}_{i, q}}(\operatorname{alt}(w, t))$ : the vase does not fall in $w^{\prime}$ (presupposition: $\exists i$ : $\operatorname{RESP}(i, q)$ )

The main clause in (19-a) conveys that Jim must catch the vase. The (subjunctive) clause (19-b), that avant que takes as an argument, conveys that the vase falls. As for the apprehensive avant que clause, (19-c) - which takes the main clause as argument - it conveys the temporal meaning that for all times preceding or simultaneous to the time at which the main clause is instantiated, the vase did not fall. Additionally, the apprehensive avant que clause (19-c) comes with the definedness condition that, given the course of events up to the time at which the main clause is instantiated, the vase has a reasonable chance of falling as well as a reasonable chance of not falling. Finally, the apprehensive avant que clause (19-c) conveys the invited inference that the goal of the agent responsible for the action described by the main clause is that the vase does not fall.

$$
[[(17)]]=\lambda w \cdot \lambda t \text {. }
$$

a. $\quad$ Temporal meaning: Jim catches the vase in $w$ at $t$ and $\neg \exists t^{\prime}\left[t^{\prime} \leq t\right.$ such that the vase falls at $t^{\prime}$ in $w$ ]

b. $\quad$ Definedness condition: $\exists w^{\prime} \in \operatorname{alt}(w, t)$ : the vase falls in $w^{\prime}$ and $\exists w^{\prime \prime} \in$ $\operatorname{alt}(w, t)$ : the vase does not fall in $w^{\prime \prime}$

c. Invited inference: $\forall w^{\prime} \in \operatorname{Best}_{\mathrm{TELEO}_{i, q}}(\operatorname{alt}(w, t))$ : the vase $\underline{\text { does not fall }}$ in $w^{\prime}$

where $q=$ Jim catches the vase

(presupposition: $\exists i$ : $\operatorname{RESP}(i, \lambda w$. Jim catches the vase in $w)$ )

Putting it together, (20) conveys that Jim must catch the vase and that, for all times preceding or simultaneous to the time at which Jim must catch the vase, the vase didn't fall. (20) also conveys that, given the course of events up to the time 
where Jim must catch the vase, the vase has a reasonable chance of falling as well as a reasonable chance of not falling. Finally, (20) conveys that the goal of the agent of the main clause (i.e., Jim), responsible for the action of catching the vase, is that the vase does not fall.

\subsection{Deriving the frustrative use}

Next, we turn to the frustrative use of avant que, as in (21).

$$
\begin{aligned}
& \text { Catherine ne se couchera pas avant qu' elle (n') } \\
& \text { Catherine NEG REFL go-to-bed-3SG.FUT not before that she EXNEG } \\
& \text { ait retrouvé son bracelet de perles. } \\
& \text { have-3SG.SBJV found her bracelet of pearls } \\
& \text { 'Catherine won't go to bed before she has found her pearl bracelet.' }
\end{aligned}
$$

With the frustrative use, the temporal meaning, given in (22-a), comes with the definedness condition that the avant que clause is nonveridical in (22-b). The frustrative use additionally comes with an invited inference of negative reason, in (22-c). This inference conveys that all the historical alternatives of $w$ at $t$ which are the most compatible with what is normally the case according to the agent $i$ responsible for the (coercitive) action described by $q$, are not- $p$-worlds.

$\left[\left[\right.\right.$ avant $\left.\left.q u e_{\text {frustrative }}\right]\right]=\lambda p \cdot \lambda q \cdot \lambda w \cdot \lambda t$.

a. Temporal meaning: $\langle w, t\rangle \in q$ and $\neg \exists t^{\prime}\left[t^{\prime} \leq t\right.$ and $\left.\left\langle w, t^{\prime}\right\rangle \in p\right]$

b. Definedness condition: $\exists w^{\prime} \in \operatorname{alt}(w, t): p\left(w^{\prime}\right)$ and $\exists w^{\prime \prime} \in \operatorname{alt}(w, t)$ : $\neg p\left(w^{\prime \prime}\right)$

c. Invited inference: $\forall w^{\prime} \in \operatorname{Best}_{\operatorname{STEREO}_{i, q}}(\operatorname{alt}(w, t)): \neg p\left(w^{\prime}\right)$ (presupposition: $\exists i$ : $\operatorname{RESP}(i, q)$ )

Applying this semantics to (21), we obtain:
a. $\quad[$ FUTURE (Catherine ne se couche pas) $]]=\lambda w$. Catherine doesn't go to bed in $w$
b. $\quad[$ SBJV (PAST $($ elle retrouve son bracelet $))]=\lambda w$. Catherine finds her bracelet in $w$
c. $\quad[$ avant qu'elle (n')ait retrouvé son bracelet $]]=\lambda q . \lambda w \cdot \lambda t$.

(i) Temporal meaning: $\langle w, t\rangle \in q$ and $\neg \exists t^{\prime}\left[t^{\prime} \leq t\right.$ such that Catherine finds her bracelet at $t^{\prime}$ in $\left.w\right]$

(ii) Definedness condition: $\exists w^{\prime} \in \operatorname{alt}(w, t)$ : Catherine finds her bracelet in $w^{\prime}$ and $\exists w^{\prime \prime} \in \operatorname{alt}(w, t)$ : Catherine does not find her bracelet in $w^{\prime \prime}$ 
Apprehensive and frustrative uses of before

(iii) Invited inference: $\forall w^{\prime} \in \operatorname{Best}_{\mathrm{STEREO}_{i, q}}(\operatorname{alt}(w, t))$ : Catherine does not find her bracelet in $w^{\prime}$

(presupposition: $\exists i$ : $\operatorname{RESP}(i, q)$ )

The main clause (23-a) conveys that Catherine does not go to bed (in the future). The (past subjunctive) clause (23-b) that avant que takes as argument conveys that Catherine finds her (pearl) bracelet. The frustrative avant que clause (23-c) - taking the main clause as argument - conveys the temporal meaning that, for all times preceding or simultaneous to the time at which the main clause is instantiated, Catherine did not find her bracelet. The frustrative avant que clause in (23-c) also comes with the definedness condition that, given the course of events up to the time at which the main clause is instantiated, she has a reasonable chance of finding her bracelet as well as a reasonable chance of not finding it. (23-c) also comes with the invited inference that the (stereotypical) expectation of the agent responsible for the action described by the main clause is that Catherine does not find her bracelet back.

$[[(21)]]=\lambda w \cdot \lambda t$.

a. $\quad$ Temporal meaning: Catherine doesn't go to bed in $w$ at $t$ and $\neg \exists t^{\prime}\left[t^{\prime} \leq t\right.$ such that Catherine finds her bracelet at $t^{\prime}$ in $w$ ]

b. $\quad$ Definedness condition: $\exists w^{\prime} \in \operatorname{alt}(w, t)$ : Catherine finds her bracelet in $w^{\prime}$ and $\exists w^{\prime \prime} \in \operatorname{alt}(w, t)$ : Catherine does not find her bracelet in $w^{\prime \prime}$

c. Invited inference: $\forall w^{\prime} \in \operatorname{Best}_{\text {STEREO }_{i, q}}(\operatorname{alt}(w, t))$ : Catherine does not find her bracelet in $w^{\prime}$

where $q=$ Catherine doesn't go to bed

(presupposition: $\exists i$ : $\operatorname{RESP}(i, \lambda w$. Catherine doesn't go to bed in $w)$ )

Overall, (24) conveys that Catherine doesn't go to bed (in the future) and that for all times preceding or simultaneous to the time at which Catherine doesn't go to bed, Catherine did not find her bracelet back. Further, (24) conveys that given the course of events up to the time where Catherine does not go to bed, she has a reasonable chance of finding her bracelet as well as a reasonable chance of not finding it. Finally, (24) conveys that the (stereotypical) expectation of the agent of the main clause, responsible for the action of not going to bed (i.e., Catherine), is that she doesn't find her bracelet back.

\section{What about expletive negation?}

This section addresses the question of what are the reasons behind the frequent occurrence of expletive negation (in naturally occurring data) in apprehensive and frustrative avant que clauses ... and beyond. Section 4.1 proposes that expletive ne is a modal negation that enters modal harmony with the negative preference component 
conveyed as an invited inference by these two uses of avant que. Section 4.2 argues, based on a diachronic corpus study focused on French data, that expletive negation enters modal harmony with a negative preference component, either conveyed at the pragmatic level (by avant que) or at the truth-conditional level (with other contexts). Section 4.3 gives a semantics for apprehensive attitudes and exceptive connectives, with the aim of accounting for the robust tendency of expletive negation to occur in the argument clause of these contexts, through the history of French.

\subsection{A modal harmony item}

In this section, I propose that the negator $n e$, when $n e$ is the sole negator and has a distribution limited to (broadly speaking) apprehensive attitudes, exceptive connectives (e.g., unless, without), prospective temporal connectives (e.g., before, until) and comparative clauses, is expressing a preference towards not- $p$. This proposal is in line with several others, for which expletive negation conveys an expressive meaning of negative preference (which, along the lines of Yoon (2011); Zovko-Dinkovic (2017) and Liu (2019), is conveyed as a conventional implicature). The novelty of my approach consists in arguing that speakers chose to use expletive negation, which is optional in French, to put emphasis on (or 'select', Bordería \& Schwenter 2005) the negative preference component of the matrix predicate. Indeed, I propose that this (modal) negator enters modal harmony with predicates that express a negative preference. Modal harmony - or modal concord - (after the notions in Lyons 1977; Huitink 2012; Giannakidou \& Mari 2018) is the phenomenon whereby two modal elements (in general, a modal verb and a modal adverb) bearing (quasi-)similar modal meaning yield a unitary (vs. a cumulative) reading. If the point I am making is right and expletive negation enters modal harmony with the invited inference of negative (teleological or stereotypical) preference that enriches the meaning of avant que in French, then it is chosen by speakers to put emphasis on it. This proposal is building on Mari \& Tahar (2020); Tahar \& Mari (2021)'s diachronic back-up story. These authors argue that French expletive negation originates from the Latin prohibitive negation, a negation marker whose distribution is restricted to imperative clauses (whether root imperatives or embedded imperatives). They argue that in French, the Latin negator turns 'expletive' with the development of proposition embedding (within the CP-field headed by the complementizer que), as it grammaticalizes into a modal negator (see also Abels 2005; Zovko-Dinkovic 2017 ) to enter modal harmony with the matrix predicate. This proposal relies on the assumption that prohibitive negation, and later expletive negation, both convey a meaning of negative preference. 
Apprehensive and frustrative uses of before

\subsection{Expletive negation beyond avant que}

\begin{tabular}{c|c|c|c}
\hline \hline & $\mathbf{N}^{\circ}$ of words & \multicolumn{2}{|c}{ Craindre } \\
& & que & que ... ne ExNeg $_{\text {ExN }}$ \\
\hline (1) & 2445405 & 6 & $\mathbf{1 1}$ \\
$(2)$ & 9995088 & 4 & $\mathbf{2 1}$ \\
$(3)$ & 14701299 & 114 & $\mathbf{1 6 5}$ \\
$(4)$ & 21661328 & 25 & $\mathbf{5 9 6}$ \\
(5) & 74652159 & 27 & $\mathbf{1 0 4 9}$ \\
\hline \hline
\end{tabular}

Table 1: Distributions of expletive negation with craindre ('fear')

\begin{tabular}{c|c|c|c}
\hline \hline & $\mathbf{N}^{\circ}$ of words & \multicolumn{2}{|c}{ A moins que } \\
& & que & que ... ne exxNeg $_{\text {Ex }}$ \\
\hline (1) & 2445405 & 0 & 0 \\
$(2)$ & 9995088 & 1 & 0 \\
$(3)$ & 14701299 & 2 & 3 \\
(4) & 21661328 & 55 & $\mathbf{5 9 1}$ \\
(5) & 74652159 & 129 & $\mathbf{1 3 4 3}$ \\
\hline \hline
\end{tabular}

Table 2: Distributions of expletive negation with à moins que ('unless')

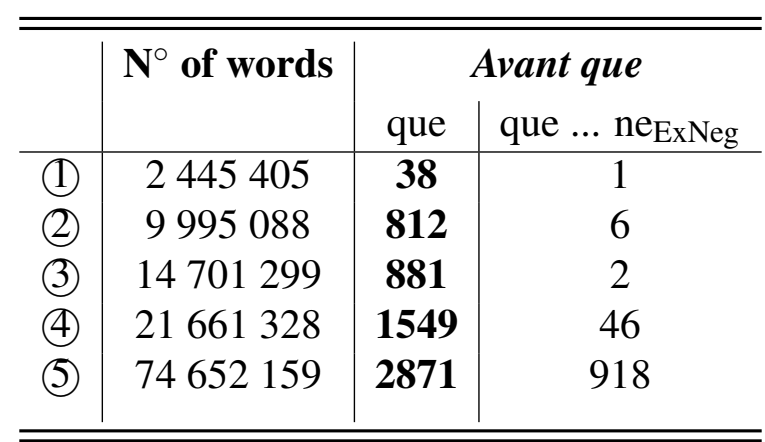

Table 3: Distributions of expletive negation with avant que ('before') 
This section aims at comparing the distribution of expletive negation in avant que clauses and in clauses introduced by other predicates. If, as Section 4.1 says, expletive negation is chosen to select the invited inference of negative preference that avant que conventionalizes, is it the case accross contexts? Could expletive negation select a component conveyed at another level? On the basis of which criteria can we find this out? The study presented here was conducted on a corpus of historical texts from French. It compares the distribution of expletive negation with (i) the apprehensive attitude craindre ('fear'), (ii) the exceptive connective $\grave{a}$ moins que ('unless') and (iii) the temporal connective avant que ('before'). It is based on the Frantext corpus, divided into 5 periods: (1) Old French (1100-1330), (2) Middle French (1330-1550), (3) Renaissance French (1550-1650), (4) Classical French (1650-1750), (5) Modern French (1750-1950).

Two observations can be made. First: throughout the history of French, the occurrence of expletive negation with avant que is infrequent (but increasing by period (5)). Second: on the contrary, with craindre and à moins que, expletive negation is robust. ${ }^{9}$ On the basis of these observations, I propose that expletive negation stands in modal harmony with a component conveyed at the pragmatic level by avant que (by invited inferences). I also conclude that expletive negation stands in modal harmony with a component conveyed at the truth-conditional level by craindre and à moins que, which leads us to the next section.

\subsection{Hard-wired negative preferences}

Expletive negation is especially robust with craindre ('fear') and à moins que ('unless'). These are 'lower-end degree modals' (an expression from Kratzer 2013), that is to say lexically negative modals with a degree semantics assigning a certain 'negative' degree (Heim 2006) of the gradable property at hand (e.g.; desirability, for craindre; likelihood, for à moins que) to the complement $p$. I'll propose two ingredients to build their semantics. First, focus-sensitivity. Craindre and à moins que are both focus-sensitive. The proposition they take as argument is compared to a set of alternative propositions, the comparison class $C$, arising from (contrastive) focus (in the line of reasoning of Heim (1992); Villalta (2008) and also Dretske (1972)). Second, a comparison of inferiority. The proposition that craindre and $\grave{a}$ moins que take as argument is involved in a comparison with the modal alternatives in $C$. They convey a 'less-than' comparative meaning that can be captured with a degree-based semantics for comparatives (see also Villalta 2008; Romero 2016) à la Seuren (1973). Both craindre and à moins que convey that the proposition they take as argument doesn't reach a certain degree $d$ of the gradable property at hand,

9 Note that à moins que only emerges as a connective by 1650 (period (4)), a pattern that matches that of English unless, see Traugott (1997)'s diachronic study. 
Apprehensive and frustrative uses of before

that the modal alternatives reach. Now that we have these two ingredients in hand, let's focus on each of these predicates. Fear verbs (craindre) involve different modal layers (Anand \& Hacquard 2013): a doxastic one (25-a) and a dispreferential one (25-b).

$[[$ craindre $]]=\lambda a \cdot \lambda p \cdot \lambda w$.

a. Doxastic meaning: $\exists w^{\prime} \in \operatorname{Dox}_{a}(w): p\left(w^{\prime}\right)$

b. Undesirability meaning: $\forall w^{\prime} \in \operatorname{Dox}_{a}(w): \forall q \in C \rightarrow q \neq p$ : $\exists d\left[\right.$ Desirability $\left.\left(\operatorname{Sim}_{w}^{\prime}(q)\right) \geq d \wedge \neg \operatorname{Desirability}\left(\operatorname{Sim}_{w}^{\prime}(p)\right) \geq d\right]$

The dispreferential layer in (25-b) assigns a little degree of desirability to the $p$ doxastic alternatives, as compared to their contextual alternatives $q$ belonging to the comparison class $C$. As for the à moins que-connective, it is generally equated to a negative conditional clause. With Leslie (2009) (refining the account of von Fintel (1991)), in a construction like [ $q$ [unless $p$ ]] the unless clause substracts $p$-worlds from the domain of a covert universal quantifier - ranging over contextually relevant (or doxastic) worlds - which takes scope over $q$-worlds, see (26-a). Further, Traugott (1997) argued that unless in English originates from the grammaticalization of the comparative adverb of inferiority (on) less than. This diachronic origin, plausible for French as well (moins que > (à) moins que), would account for the connective's (modalized) comparative meaning of inferiority, in (26-b).

$[[\grave{a}$ moins que $]]=\lambda a \cdot \lambda p \cdot \lambda q=$

a. Negative conditional meaning: $\forall w^{\prime}\left[w^{\prime} \in \operatorname{Dox}_{\mathrm{a}}(w): \neg p\left(w^{\prime}\right)\right] q\left(w^{\prime}\right)$

b. Unlikelihood meaning: $\forall w^{\prime} \in \operatorname{Dox}_{a}(w): \forall r \in C \rightarrow r \neq p$ : $\exists d\left[\operatorname{Likelihood}\left(\operatorname{Sim}_{w}^{\prime}(r)\right) \geq d \wedge \neg \operatorname{Likelihood}\left(\operatorname{Sim}_{w}^{\prime}(p)\right) \geq d\right]$

The dispreferential layer in (26-b) assigns a little degree of likelihood to the $p$ doxastic alternatives, as compared to their contextual alternatives $r$ belonging to the comparison class $C$.

\section{Conclusion}

This paper proposed that the temporal meaning of before can be pragmatically enriched, when the before clause receives a non-factual interpretation, by inferences of negative purpose or negative reason. Further, it proposed that expletive negation a semantically bleached speech-act-like negation - stands in modal harmony with negative preferences, conveyed at the pragmatic level by French avant que ('before') or at the truth-conditional level, by craindre ('fear') and à moins que ('unless'). 


\section{References}

Abels, Klaus. 2005. Expletive negation in Russian : A Conspiracy Theory. Journal of Slavic Linguistics 13(1). 5-74.

Anand, Pranav \& Valentine Hacquard. 2013. Epistemics and Attitudes. Semantics and Pragmatics 6. 1-59. doi:http://dx.doi.org/10.3765/sp.6.8.

Anderbois, Scott \& Maksymilian Dabkowski. 2020. A'ingae =sa'ne 'appr' and the semantic typology of apprehensional adjuncts. In Semantic and Linguistic Theory (SALT) 30, doi:https://doi.org/10.3765/salt.v30i0.4804.

Angelo, Denise \& Eva Schultze-Berndt. 2016. Beware bambai: lest it be apprehensive. In Loss and Renewal. Australian languages since colonisation, 254-296. Walter De Gruyter. doi:https://doi.org/10.1515/9781614518792-015.

Anscombe, Elizabeth. 1964. Before and After. In The Philosophical Review, 3-24. doi:https://doi.org/10.2307/2183199.

Beaver, David \& Cleo Condoravdi. 2003. A unified analysis of Before and After. In Semantic and Linguistic Theory (SALT), vol. 13, 37-54. doi:https://doi.org/10.3765/salt.v13i0.2899.

Bordería, Salvador \& Scott Schwenter. 2005. Polar meaning and 'expletive' negation in approximative adverbs: Spanish. Journal of Historical Pragmatics 6. 262-282. doi:https://doi.org/10.1075/jhp.6.2.06pon.

Condoravdi, Cleo. 2001. Temporal Interpretation of Modals - Modals for the Present and for the Past. In The Construction of Meaning, 59-88. CSLI Publications.

Condoravdi, Cleo. 2010. NPI-licensing in temporal clauses. Natural Language and Linguist Theory 28. 877-910.

Del Prete, Fabio. 2008. A non-uniform semantic analysis of the italian temporal connectives Prima and Dopo. Natural Language Semantics 16. doi:https://doi.org/10.1007/s11050-008-9030-6.

Dretske, Fred. 1972. Contrastive Statements. The Philosophical Review 81(4). 411-437. doi:https://doi.org/10.2307/2183886.

Giannakidou, Anastasia. 1998. Polarity Sensitivity as (Non)veridical Dependency. John Benjamins.

Giannakidou, Anastasia. 1999. Affective Dependencies. Linguistics and Philosophy 22. 367-421. doi:https://doi.org/10.1023/A:1005492130684.

Giannakidou, Anastasia. 2009. The dependency of the subjunctive revisited: temporal semantics and polarity. Lingua 120. 1883-1908. doi:https://doi.org/10.1016/j.lingua.2008.11.007.

Giannakidou, Anastasia. 2011. (non)veridicality and mood choice: Subjunctive, polarity, and time. In Renate Musan \& Monika Rathert (eds.), Tense across Languages, 59-90. Berlin, Boston: De Gruyter. doi:https://doi.org/10.1515/9783110267020.59. 
Apprehensive and frustrative uses of before

Giannakidou, Anastasia. 2014. The prospective as nonveridical: polarity items, speaker commitment and projected truth. In The Black Book: Feestschrift for Frans Zwarts, 101-124.

Giannakidou, Anastasia \& Alda Mari. 2013. A two dimensional analysis of the future: modal adverbs and speaker's bias. In Amsterdam Colloquium 19th, 115-122.

Giannakidou, Anastasia \& Alda Mari. 2016. Emotive predicates and the subjunctive: a flexible mood OT account based on (non)veridicality. In Sinn und Bedeutung 20, 288-305.

Giannakidou, Anastasia \& Alda Mari. 2017a. Epistemic future and epistemic must: Nonveridicality, evidence, and partial knowledge: In Joanna Blaszczak, Anastasia Giannakidou, Dorota Klimek-Jankowska \& Krzysztof Migdalski (eds.), Mood, Aspect, Modality Revisited: New Answers to Old Questions, 75-118. Chicago: University of Chicago Press. doi:https://doi.org/10.7208/9780226363660-004.

Giannakidou, Anastasia \& Alda Mari. 2017b. A unified analysis of the future as epistemic modality: the view from Greek and Italian. Natural Language Linguistic Theory (36(1)). 85-129. doi:https://doi.org/10.1007/s11049-0179366-z.

Giannakidou, Anastasia \& Alda Mari. 2018. The semantic roots of positive polarity: epistemic modal verbs and adverbs in Greek and Italian. Linguistics and Philosophy 41(6). 623-664. doi:https://doi.org/10.1007/s10988-018-9235-1.

Giannakidou, Anastasia \& Alda Mari. 2021. (Non)Veridicality in Grammar and Thought. University of Chicago Press.

Giannakidou, Anastasia \& Franz Zwarts. 1999. Aspectual properties of temporal connectives. In Greek Linguistics' 97: 3rd International Conference on Greek Linguistics, 104-113. Ellinika Grammata, Athens.

Heim, Irene. 1992. Presupposition Projection and the Semantics of Attitude Verbs. Journal of Semantics 9(3). 183-221. doi:https://doi.org/10.1093/jos/9.3.183.

Heim, Irene. 2006. Little. In Semantics and Linguistic Theory (SALT) 16, 35-58. doi:https://doi.org/10.3765/salt.v16i0.2941.

Heinämäki, Orvokki. 1974. Semantics of English temporal connectives: University of Texas PhD dissertation.

Huitink, Janneke. 2012. Modal concord: a case study of Dutch. Journal of Semantics 29(3). 403-437. doi:https://doi.org/10.1093/jos/ffr012.

Israel, Michael. 1996. Polarity sensitivity as lexical semantics. Linguistics and Philosophy 19. 619-666. doi:https://doi.org/10.1007/BF00632710.

Kratzer, Angelika. 1991. Modality. In A. von Stechow \& D. Wunderlich (eds.), Semantics: An International Handbook of Contemporary Research, 639-650. Berlin : Mouton de Gruyter. 
Kratzer, Angelika. 2013. Modality for the 21st century. In The Language Cognition Interface / L'Interface Language-Cognition, 179-199. Geneva-Paris: Librairie Droz.

Krifka, Manfred. 2010. How to interpret expletive negation under bevor in German. In Thomas Hanneforth \& Gisbert Fanselow (eds.), Language and Logos. Studies in Theoretical and Computational Linguistics, 214-236. Akademie Verlag.

Kroeger, Paul. 2017. Frustration, culmination and inertia in kimaragang grammar. Glossa: a journal of general linguistics 2(1). 1-29. doi:doi: https://doi.org/10.5334/gjgl.146.

Kuteva, Tania, Bas Aarts, Gergana Popova \& Anvita Abbi. 2019. The grammar of 'non-realization'. Studies in Langage 43(4). 850-895. doi:https://doi.org/10.1075/sl.18044.kut.

Ladusaw, William. 1996. Negation and polarity items. In Shalom Lappin (ed.), The Handbook of Contemporary Semantic Theory, 321-341. Blackwell Reference.

Leslie, Sarah-Jane. 2009. If, unless and quantification. In Robert Stainton \& Christopher Viger (eds.), Compositionality, Context and Semantics, 3-30. Dordrecht: Springer. doi:https://doi.org/10.1007/978-1-4020-8310-5_1.

Lichtenberk, Frantisek. 1995. Apprehensional epistemics. In Joan Bybee \& Joan Fleischman (eds.), Modality in Grammar and Discourse, 293-328. John Benjamins Publishing Company.

Liu, Migya. 2019. The semantics and pragmatics of chadian-mei in mandarin chinese. Linguistische Berichte 258. 229-254.

Lyons, John. 1977. Semantics. Cambridge University Press.

Mari, Alda. 2017. Actuality entailments : when the modality is in the presupposition. Lecture Notes in Computer Science 191-210. 191-210. doi:https://doi.org/10.1007/978-3-662-53826-5_12.

Mari, Alda \& Chloé Tahar. 2020. Negative priorities: evidence from prohibitive and expletive negation. In Sinn und Bedeutung 24(2), 56-71. doi:https://doi.org/10.18148/sub/2020.v24i2.886.

Ogihara, Toshiyuki. ???? Non-factual 'before' and adverbs of quantification. In Semantic and Linguistic Theory (SALT) 5, 273-291. doi:https://doi.org/10.3765/salt.v5i0.2698.

Overall, Simon. 2017. A typology of frustrative marking in amazonian languages. In Alexandra Aikhenvald \& R. M. W Dixon (eds.), The Cambridge Handbook of Linguistic Typology, 477-512. Cambridge University Press.

Portner, Paul. 2007. Imperatives and modals. Natural Language Semantics 15. 351-383. doi:https://doi.org/10.1007/s11050-007-9022-y.

Portner, Paul. 2009. Modality. Oxford University Press.

Romero, Maribel. 2016. Surprise-predicates, strong exhaustivity and alternative questions. In Semantic and Linguistic Theory (SALT) 25, 225-245. 
Apprehensive and frustrative uses of before

doi:https://doi.org/10.3765/salt.v25i0.3081.

Rubinstein, Aynat. 2012. Roots of Modality: UMass Amherst PhD dissertation.

Seuren, Pieter. 1973. The comparative. In Ferenc Kiefer \& Nicolas Ruwet (eds.), Generative grammar in Europe, 528-564. Reidel: Dordrecht.

Tahar, Chloé \& Alda Mari. 2021. Turning expletive: from embedded speech-acts to embedded propositions. Manuscript IJN.

Thompson, Sandra, Robert Longacre \& Shin Ja Hwang. 2007. Adverbial clauses. In Language Typology and Syntactic Description, 237-300. Cambridge: Cambridge University Press.

Traugott, Elizabeth. 1997. Unless and but conditionals: a historical perspective. In Angeliki Athanasiadou \& René Dirven (eds.), On conditionals again, 145-165. Current Issues in Linguistic Theory. doi:https://doi.org/10.1075/cilt.143.09clo.

Verstraete, Jean-Christophe. 2008. The status of purpose, reason, and intended endpoint in the typology of complex sentences: Implications for layered models of clause structure. Linguistics 46(4). 757-788. doi:https://doi.org/10.1515/LING.2008.025.

Villalta, Elisabeth. 2008. Mood and gradability: An investigation of the subjunctive mood in spanish. Linguistics and Philosophy 31(4). 467-552. doi:https://doi.org/10.1007/s10988-008-9046-x.

von Fintel, Kai. 1991. Exceptive Conditionals: The Meaning of Unless. In North East Linguistic Society (NELS) 22, 135-151.

Vuillermet, Marine. 2018. Grammatical Fear morphemes in Ese Ejja: Making the case for a morphosemantic apprehensional domain. Studies in Language 42(2). 256-293. doi:https://doi.org/10.1075/sl.00010.vui.

Yanovitch, Igor. 2013. Four pieces for modality, context and usage: Massachussets Institute of Technology PhD dissertation.

Yoon, Suwon. 2011. Not in the Mood: the syntax, semantics and pragmatics of evaluative negation: University of Chicago $\mathrm{PhD}$ dissertation.

Zaradzki, Léo. 2020. Verbal negation. In Sinn und Bedeutung 24(2), 485-502. doi:https://doi.org/10.18148/sub/2020.v24i2.911.

Zovko-Dinkovic, Irena. 2017. Pleonastic negation from a cross-linguistic perspective. Jezikoslovje 18. 159-180.

Zwarts, Frans. 1995. Nonveridical contexts. Linguistic Analysis 25. 286-312. 
Chloé Tahar

Institut Jean Nicod

Ecole Normale Supérieure

29 rue d'Ulm

75005, Paris

France

chloe.tahar@gmail.com 